\title{
Paracoccidioidomicosis en caninos y felinos: hallazgos clínicos, diagnóstico y tratamiento
}

\author{
Canine and feline paracoccidioidomycosis. Clinical findings, diagnosis \\ and treatment
}

\author{
Martínez Cepeda galo Ernesto ${ }^{1,2^{*}}$, Revelo Ruales alexandra Paola 3
}

1. Carrera de Medicina Veterinaria y Zootecnia, Facultad de Medicina Veterinaria y Zootecnia de la Universidad de Guayaquil. 2. Centro de Diagnóstico Veterinario "Santo Domingo". 3. Instituto Nacional de Investigación en Salud Pública Dr. Leopoldo Izquieta Pérez, CuencaEcuador.

* Correo electrónico del autor de contacto: galomartinez88@gmail.com

\begin{abstract}
Resumen
La paracoccidioidomicosis es una micosis profunda endémica de América Latina. Se ha identificado Paracoccidioides spp. en diferentes especies animales. En caninos y felinos, se presenta con una signología inespecífica con alteraciones de los sistemas respiratorio y nervioso y, menos frecuentemente, con alteraciones cutáneas. La presentación leve y de resolución espontánea de la enfermedad depende del estado inmunológico del animal; una respuesta inmune deficiente permite que se disemine y pueda llegar hasta la muerte. Existen varias técnicas disponibles para su diagnóstico. El diagnóstico definitivo se realiza identificando a Paracoccidioides spp. mediante cultivo, aislamiento y posterior identificación molecular. La realización de esta revisión bibliográfica tuvo la finalidad de recopilar información sobre esta enfermedad de interés en caninos y felinos.
\end{abstract}

\section{Palabras clave}

Paracoccidioidomicosis, signos clínicos, diagnóstico, tratamiento, caninos, felinos

\begin{abstract}
Paracoccidioidomycosis is an endemic deep mycosis of Latin America. Paracoccidioides spp. has been identified in different animal species. Clinical signs of paracoccidiomycosis in dogs and cats are nonspecific and include alterations of the respiratory and nervous system, and less frequently, cutaneous alterations. The mild presentation and spontaneous resolution of the disease depends on the immune status of the animal, and a poor immune response results in pathogen dissemination and possibly death. Several techniques are available for diagnosis; definitive diagnosis is based on identification of Paracoccidioides spp. by culture, isolation and subsequent molecular characterization. This review aimed to collect relevant information on this canine and feline disease.
\end{abstract}

\section{Key words}

Paracoccidioidomycosis, clinical signs, diagnosis, treatment, canine, feline

Fecha de recepción: 15/03/2018

Fecha de aprobación: 15/07/2018
ANALECTA VeT 2018; Julio-Diciembre; 38(2):22-31

Impresa ISSN 03655 14-8 Electrónica ISSN 1514-2590

doi.org/10.24215/15142590eo29 


\section{Introducción}

La paracoccidioidomicosis es una micosis de curso crónico, causada por el hongo dimórfico Paracoccidioides, del cual se han identificado cinco especies: $P$. brasiliensis, $P$. americana, $P$. restrepiensis, $P$. venezuelensis, y P. lutzii (Hrycyk et al., 2018). P. brasiliensis está distribuido ampliamente en América del Sur y se ha asociado con la mayoría de los casos de paracoccidioidomicosis detectados hasta la actualidad, mientras que $P$. lutzii se ha encontrado en el centro, suroeste y norte de Brasil y Ecuador (Teixeira et al., 2014).

La paracoccidioidomicosis es una enfermedad endémica de áreas rurales y subtropicales de América del Sur. Sin embargo, en Chile y las Guayanas no se han presentado casos. El país con mayor cantidad de casos informados es Brasil. En Argentina, las áreas endémicas están ubicadas en las provincias de Chaco, Formosa, Misiones, Corrientes, norte de Entre Ríos, Sante Fe, Tucumán y Salta (Ballesteros et al. 2014).

La mayoría de los casos se presentan en humanos, en quienes se considera una enfermedad ocupacional (Pérez et al., 2014). Los caninos, felinos (con menor frecuencia), bovinos, equinos y pequeños rumiantes como la oveja son las especies domés-ticas afectadas (Corte et al., 2012).

\section{Historia de la enfermedad}

Fue informada por primera vez en humanos por Adolf Lutz en Brasil (Marques, 2012). En Argentina, Brasil, Colombia, Ecuador y Venezuela, la enfermedad se circunscribe a las áreas rurales (Brummer \& Castaneda 1993).

El primer caso en humanos fue estudiado por Lutz en 1908 al realizar el diagnóstico diferencial en dos pacientes que presentaban múltiples lesiones en la mucosa orofaríngea muy similares a un carcinoma de células escamosas. Además de las lesiones en la mucosa oral, los individuos presentaban adenopatías cervicales. Lutz tomó muestras de las lesiones y observó células levaduriformes grandes y esféricas, multibrotantes; esas células no eran conocidas hasta el momento como agente etiológico de ninguna enfermedad, por lo que se denominó "micosis pseudococcídica" (Conti Díaz, 2010; Marques, 2012).

En 1912, Splendore estudió la micromorfología del hongo, lo consideró como un ascomiceto y lo denominó Zimonema brasiliensis (Conti Díaz 2010). En 1930, Almeida le asignó el nombre de Paracoccidioides brasiliensis y esclareció las diferencias morfológicas entre las fases micelial y levaduriforme al compararlo con las mismas fases del Coccidioides spp. (Conti Díaz, 2010).

La enfermedad era mortal hasta el descubrimiento de la eficacia de las sulfonamidas. Asimismo, entre los antifúngicos, la anfotericina B fue utilizada por primera vez para el tratamiento de esta enfermedad en 1958 y, en 1980, se incluyeron los azoles en el esquema terapéutico (Marques, 2012).

\section{Agente etiológico}

La paracoccidioidomicosis, también conocida como blastomicosis sudamericana, blastomicosis latinoamericana, enfermedad de LutzSplendore-Almeida o granuloma paracoccidioidal, es causada por el hongo $P$. brasiliensis, sus variantes S1, PS2, PS3, PS4 y Paracoccidioides lutzii (Machado et al., 2013; Teixeira et al., 2014) . El hongo presenta dimorfismo termal. En cultivos a $37^{\circ} \mathrm{C}$ crece en forma de levadura y forma colonias blancas y brillantes, de aspecto cremoso en medios sólidos (Brummer \& Castaneda, 1993). En medio de cultivo líquido crece formando acúmulos de distinto tamaño. El tiempo de incubación fluctúa entre 10 y 15 días. Las células miden entre 4 y 30 $\mu \mathrm{m}$, poseen una forma oval alargada $\mathrm{y}$ son refractarias a la luz.

La forma micelial presenta colonias de color blanquecino, de forma irregular con micelios aéreos cortos. El tiempo de incubación es de 20 a 30 días a temperatura de 20 a $26{ }^{\circ} \mathrm{C}$ (Brummer \& Castaneda, 1993; Marques, 2012). En algunos cultivos es posible observar la producción de un pigmento marrón. Microscópicamente el hongo posee hifas delgadas, hialinas y septadas; en medios de cultivo comunes suele formar clamidosporas. Los medios utilizados con mayor frecuencia para el cultivo son el agar Sabouraud y el medio infusión cerebro corazón (BHI).

Además, es posible aislar el hongo de tejidos de monos ardilla (Saimiri sciureus), murciélagos frugívoros (Artibeus lituratus) y pingüinos (Pygoscelis adeliae). El armadillo (Daypus novemcinctus) suele estar infectado pero no manifiesta los signos de la enfermedad. Otras especies de animales en las cuales se pudo identificar la presencia del hongo por medio de técnicas moleculares son: cuis (Cavia aperea), puerco espín (Sphiggurus spinosus), mapache (Procyon cancrivorus), grisón (Galictis vittata) y armadillos (D. novemcintucs y Dasypus septemcinctus) (Brummer \& Castaneda, 1993; Rojas-Jaimes et al., 2015).

Los modelos animales de experimentación como el cobayo, el hámster y el conejo son los de elección para reproducir al hongo in vivo. La inoculación del hongo en los modelos animales se realiza utilizando inóculos de concentración elevada por vía subcutánea, intramuscular, intraperitoneal, intravenosa o intratesticular (Brummer \& Castaneda, 1993).

Paracoccidioides spp. es un hongo ampliamente distribuido en zonas subtropicales y húmedas con temperaturas fluctuantes entre 18 y $23{ }^{\circ} \mathrm{C}$. En Brasil y Venezuela fue posible aislar el hongo a partir de suelos de cultivo de café, aunque su hábitat natural no está completamente dilucidado (Brummer \& Castaneda, 1993). 


\section{Clasificación taxonómica}

División: Ascomycota

Clase: Endomycetes

Orden: Onygenales

Familia: Onygenaceae

Género: Paracoccidioides

Especies: $P$. brasiliensis, $P$. americana, $P$. restrepiensis, $P$. venezuelensis $y$ P. lutzii

El estado teleomorfo de este hongo es desconocido hasta el momento.

\section{Aspectos clínicos}

La paracoccidioidomicosis es una micosis sistémica que afecta primordialmente a los pulmones desde donde se disemina por vía linfohemática a los linfonodos, piel, ojos, huesos y otros órganos. Los perros machos jóvenes de razas grandes (en especial las razas de deporte y caza) que habitan o pasan la mayor parte de su tiempo cerca del agua, presentan mayores posibilidades de contraer la enfermedad (Morgan et al., 2004).

La infección se produce por la inhalación de los conidios infectantes presentes en el ambiente. La inoculación directa puede, raramente, ocasionar enfermedad cutánea localizada. Los conidios ingresan al organismo, alcanzan el pulmón y son fagocitados por los macrófagos alveolares, luego de lo cual ocurre la transformación a levaduras, lo que produce una respuesta supurativa o piogranulomatosa. Las levaduras, al sobrevivir intracelularmente, son transportadas por los sistemas hemático y linfático; así, se diseminan y causan enfermedad sistémica (Thompson, 2008). Los órganos comúnmente afectados son los linfonodos, los ojos, la piel, los huesos, la próstata y también el tejido celular subcutáneo. En los gatos, la piel, el tejido subcutáneo, los ojos, los órganos del sistema nervioso central (SNC) y los linfonodos son los más afectados (Ettinger \& Feldman, 2004; Morgan et al., 2004; Thompson, 2008)

El periodo de incubación es variable, y suele ser de entre 5 y 12 semanas, dependiendo del grado de competencia del sistema inmunitario del huésped. La severidad de la enfermedad también depende de la magnitud de la respuesta inmunitaria (Morgan et al., 2004). Si la respuesta inmunitaria es adecuada se desencadena una enfermedad respiratoria leve de resolución espontánea, o bien un compromiso de otros sistemas, sin lesiones pulmonares. Cuando la respuesta inmunitaria es inadecuada o deficiente, es posible que la enfermedad progrese hasta la diseminación $\mathrm{y}$, además, pueda causar enfermedad pulmonar grave (Morgan et al., 2004; Thompson, 2008). Se ha reportado un caso de shock séptico fatal en una persona a causa de $P$. brasiliensis $\mathrm{S} 1$, mientras que en animales no se han reportado casos similares (Macedo et al., 2018).

\section{Manifestaciones clínicas en caninos}

En perros, el hemograma a menudo es normal. Pueden presentarse, sin embargo, anemia normocítica, normocrómica, neutrofilia y eosinofilia, pero ninguna de estas alteraciones guarda correlación con la severidad de la enfermedad (de Farias et al., 2011).

El análisis químico de la sangre frecuentemente no presenta alteraciones; las más comunes son hipoalbuminemia e hipercalcemia, aunque solo se presentan en el $10 \%$ de los casos (Ettinger \& Feldman, 2004).

Con respecto a las manifestaciones clínicas, suelen ser poco específicas, se presentan como anorexia, depresión, pérdida de peso, caquexia y fiebre, y están presentes en un $40 \%$ de los casos. Los signos clínicos en perros suelen ser tos $\mathrm{y}$ dificultad respiratoria, desde leve hasta con disnea grave. En pocos casos se observa cianosis. Por lo general, hay aumento de tamaño de los linfonodos perihiliares, con la consiguiente compresión de los bronquios principales. La enfermedad broncointersticial y alveolar es la causa de tos seca (Morgan et al., 2004).

Algunos estudios demostraron que, en caninos, entre 30 y $50 \%$ de los casos presenta lesiones cutáneas, mientras que en los gatos estas lesiones son las habituales (Morgan et al., 2004). El sistema reproductor se encuentra afectado en, aproximadamente, 5-10 \% de los perros enfermos, mientras que el compromiso del sistema nervioso puede ser menor al $5 \%$ de los casos (Ettinger \& Feldman, 2004). Los signos y lesiones oculares incluyen: conjuntivitis, edema corneal, vascularización corneal, anisocoria, uveítis anterior, glaucoma secundario, exoftalmos, coriorretinitis granulomatosa, desprendimiento de retina y neuritis óptica (Schaer, 2006).

En un estudio realizado en Brasil con suero proveniente de 836 perros se demostró la coinfección con $P$. brasiliensis y Leishmania spp. (Silveira et al., 2006). Asimismo, los perros positivos para Leishmania spp. mostraron mayor reactividad para la glicoproteína 43 -gp43- (79,9 \%) que aquellos que fueron negativos (54\%).

Tanto en perros con paracoccidiodomicosis como en perros con leishmaniasis se constata una respuesta inmunitaria de tipo Th1, lo que indicaría que los animales más propensos a contraer leishmaniasis también lo serían para desarrollar paracoccidiodomicosis (Silveira et al., 2006).

Los caninos presentan anticuerpos contra la gp43 detectables mediante la prueba de inmunodifusión, aunque no presenten signología clínica; esto no se observa en pacientes humanos, que no resultan reactivos a la prueba cuando no presentan síntomas (Silveira et al., 2006). La edad fue otro factor de riesgo analizado en el estudio de Silveira. Así, los perros menores de un año presentaron baja reactividad a la gp43 y los mayores de un año mostraron elevada reactividad 
a la glicoproteína de $P$. brasiliensis (Silveira et al., 2006).

En los exámenes radiográficos se observa un patrón intersticial en aproximadamente el 70 \% de los perros, y un patrón mixto intersticial/alveolar en un $20 \%$. En algunos casos se presenta linfadenopatía tráqueobronquial. En un 30 \% son poco frecuentes los nódulos mediastínicos o formaciones pulmonares aisladas. En ocasiones, no se observan nódulos pulmonares debido a la colecta pleural que sucede en el $7 \%$ de los casos; es muy raro que se presente neumotórax (Ettinger \& Feldman, 2004; Morgan et al., 2004).

Las lesiones óseas que se presentan en los huesos largos son de tipo osteolítico. La proliferación perióstica y la inflamación de los tejidos blandos adyacentes se aprecia en un $50 \%$ de las lesiones (Ettinger \& Feldman, 2004).

\section{Manifestaciones clínicas en felinos}

La paracoccidioidomicosis no es frecuente en gatos. La mayoría de los signos clínicos observados en perros pueden observarse también en gatos. Es destacable en los gatos el desarrollo de lesiones cutáneas: pueden observarse pápulas, nódulos o placas solitarias o múltiples, que eventualmente se ulceran o forman grandes abscesos (Morgan et al., 2004). Los órganos del sistema nervioso resulta más afectado en los gatos que en los perros (Morgan et al., 2004; Ettinger \& Feldman, 2004).

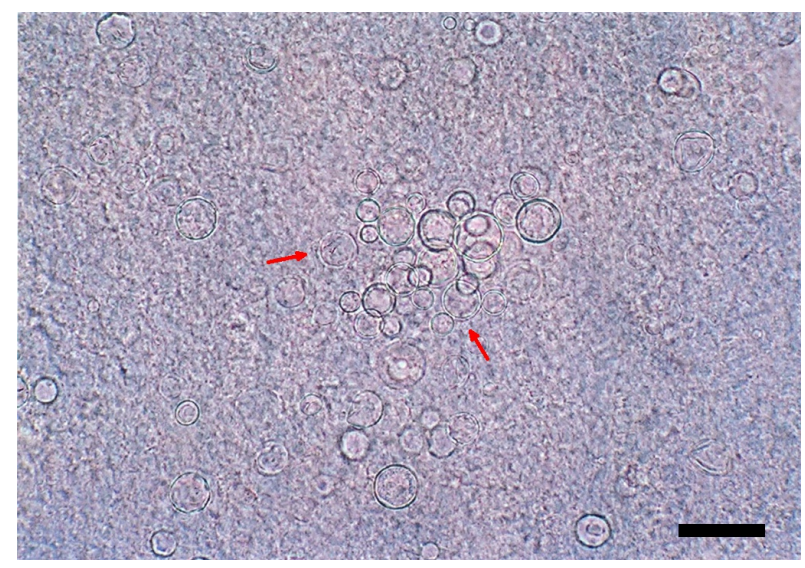

Figura 1. Fase levaduriforme de $P$. brasiliensis (flechas).

Barra $=50 \mu \mathrm{m}$. Punción de linfonódulo. Gentileza del Dr. Gustavo Giusiano.

En un estudio realizado en el norte del estado de Paraná, Brasil, sobre un total de 136 muestras de suero (86 de gatos de zonas rurales y, 50, de zonas urbanas), se demostró que los gatos de zonas rurales son especialmente susceptibles a contraer la infección (48,8\%), comparados con aquellos de zonas urbanas (2 \%). El sexo de los animales no fue un factor de riesgo. Además, se determinó una menor susceptibilidad de los gatos
(48\%), comparada con la de los perros de la misma región rural $(89,5 \%)$. Los investigadores consideran que el hábito de hozar es un factor predisponente que favorece el ingreso del hongo al organismo (Oliveira et al., 2013). Asimismo, en ese estudio, los gatos fueron más susceptibles a desarrollar las formas encefálica y urinaria (Oliveira et al., 2013).

\section{Diagnóstico diferencial}

Los principales son: coccidioidomicosis, esporotricosis, micetomas, eumicetomas, cromomicosis, nocardiosis, leishmaniasis, tularemia y tuberculosis u otras micobacteriosis.

\section{Métodos de diagnóstico}

\section{Métodos directos \\ Examen directo}

El objetivo es la búsqueda de levaduras esféricas de 12 a $20 \mu \mathrm{m}$ con doble pared refringente, vacuolas lipídicas intracitoplasmáticas y, sobre todo, el hallazgo de gemación múltiple. Las gemas adheridas a la levadura forman una figura característica llamada: "rueda de timón" (Espinoza et al., 2014). Esta figura es considerada patognomónica y de esta manera puede formularse un diagnóstico definitivo. Las gemas o brotes suelen medir entre 1 y $10 \mu \mathrm{m}$ de diámetro.

Para observar la fase de levadura de Paracoccidioides spp. se puede utilizar el calco-flúor, el cual facilita la visualización del hongo. Las tinciones de Gram, Ziehl Neelsen y Giemsa no siempre facilitan la observación de las levaduras. Las técnicas de plata metenamina (Gomori-Grocott) y la reacción de PAS, en cortes histológicos, permiten observar levaduras esféricas, con o sin brotes. Las muestras ideales para la observación del agente son aquellas que se toman a partir de lesiones, de pus o mediante lavado bronquial o broncoalveolar.

\section{$\underline{\text { Cultivo }}$}

El estándar de oro es el cultivo de $P$. brasiliensis (Marques, 2012). Dependiendo de la temperatura de incubación desarrolla su fase micelial $\left(28{ }^{\circ} \mathrm{C}\right)$ o levaduriforme $\left(37^{\circ} \mathrm{C}\right)$ y es de crecimiento lento. El desarrollo en cultivos se observa en un porcentaje apreciable de los casos (6o a $80 \%$ ) (Winn et al., 2008).

Es recomendable sembrar la muestra en varios medios de cultivo, a $28{ }^{\circ} \mathrm{C}$ y $37{ }^{\circ} \mathrm{C}$. En muestras libres de contaminación, como aquellas de líquido cefalorraquídeo, incubadas a $37{ }^{\circ} \mathrm{C}$, las colonias comienzan a ser visibles alrededor del décimo día, son de consistencia cérea o pastosa, de aspecto cerebriforme, blanca y glabra. A $28{ }^{\circ} \mathrm{C}$, en agar Sabouraud, se observa una colonia de desa- 
rrollo lento, rugosa o membranosa, cubierta por un micelio aéreo blanco y por vellosidades cortas, con un tiempo de incubación de 2 a 4 semanas. El reverso de la colonia en este medio generalmente es marrón, en la mayoría de los primocultivos desarrolla colonias rugosas y cerebriformes, previo agregado de cicloheximida al medio. El aislamiento y desarrollo del hongo en cultivo son confirmatorios para el diagnóstico de la paracoccidioidomicosis en pacientes humanos y caninos con manifestaciones clínicas de la enfermedad (Brummer \& Castaneda, 1993; Pérez et al., 2014; CarrascoZuber et al., 2016) .

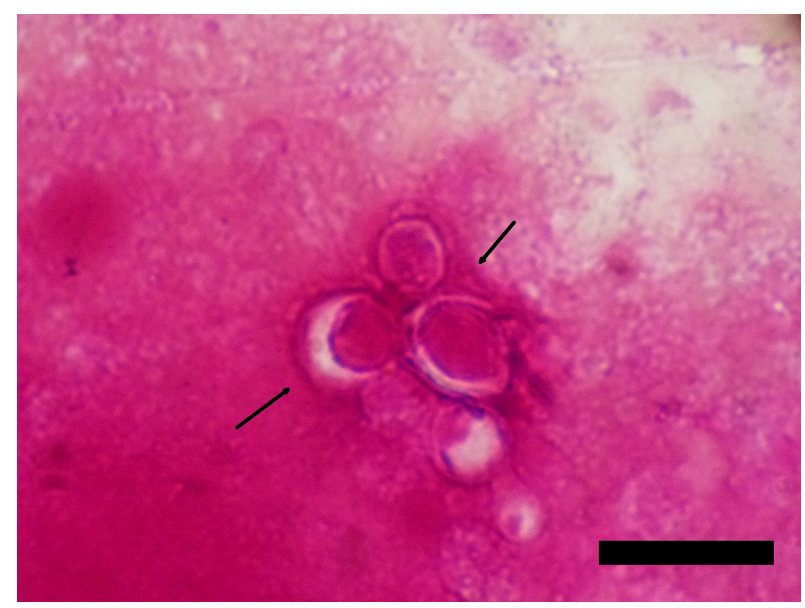

Figura 2. $P$. brasiliensis (flechas). Reacción de PAS.

Barra $=50 \mu \mathrm{m}$. Gentileza del Dr. Roberto Suárez-Álvarez. Depto. de Micología. ANLIS-INEI “Dr. Carlos G. Malbrán”.

\section{$\underline{\text { Histopatología }}$}

Microscópicamente, pueden observarse lesiones inflamatorias de tipo purulento o piogranulomatoso. Los hongos pueden colorearse mediante técnicas especiales, tales como PAS y plata metenamina (Ettinger \& Feldman, 2004).

\section{Técnicas de biología molecular}

La paracoccidioidomicosis es una enfermedad de difícil diagnóstico en sus etapas iniciales. En medicina humana, una de las técnicas de diagnóstico utilizadas actualmente es la PCR. Se desarrolló una PCR dirigida a la amplificación de la gp43, presente en el $90 \%$ de los pacientes con la enfermedad. Los cebadores diseñados resultaron de mucha especificidad y sensibilidad, superando a las pruebas de diagnóstico serológico. Se utilizaron muestras de esputo provenientes de pacientes con paracoccidioidomicosis comprobada mediante pruebas serológicas y examen directo positivo para $P$. brasiliensis. Todas las muestras evaluadas resultaron positivas para $P$. brasiliensis, lo que demostró la utilidad de la técnica para su utilización a partir de la muestra clínica, para la obtención de un diagnóstico temprano de la enfermedad, así como también por su mayor especificidad y sensibilidad con respecto a los métodos de diagnóstico convencionales (Gomes et al., 2000).

Pitz et al. (2013) propusieron la utilización de una PCR semianidada en un tubo (OTsn-PCR) para la detección de $P$. brasiliensis en muestras clínicas. La técnica demostró tener igual o mayor efectividad para el diagnóstico de la enfermedad, comparada con las técnicas clásicas de PCR anidada o semianidada, descritas años atrás por Imai et al. (2000).

\section{Métodos indirectos $\underline{\text { Inmunoserología }}$}

Los estudios inmunoserológicos para la detección de anticuerpos específicos contra $P$. brasiliensis se realizan con el uso de antígenos específicos. Estos métodos se recomiendan en pacientes sin lesiones mucocutáneas, que son las que permiten el examen directo y el cultivo.

En 1916, Moses, por primera vez, publicó una prueba de inmunodiagnóstico, mediante la utilización de un antígeno citoplasmático (Brummer \& Castaneda 1993). En 1955, Fava Netto, en Brasil, empleó por primera vez un antígeno de naturaleza polisacárida para las pruebas de fijación del complemento y de precipitinas en tubo. En 1973, Yarzábal et al. utilizaron la inmunoelectroforesis (IEF) para el diagnóstico de paracoccidioidomicosis. Restrepo et al. (1974) fueron los primeros en proponer la técnica de doble difusión en agar o inmunodifusión simple (ID) para el diagnóstico serológico de la enfermedad; esta técnica fue posteriormente utilizada en muchos países. La ID es una prueba de screening y de diagnóstico, con 89 a $91 \%$ de sensibilidad y especificidad, respectivamente (Mendes-Giannini \& Camargo, 1984; Brummer \& Castaneda, 1993; Conti Díaz, 2010).

En 1972, Restrepo utilizó la inmunofluorescencia indirecta como técnica de diagnóstico, con una especificidad del $90 \%$ y una sensibilidad del 65 \% (Restrepo, 1972).

La prueba de aglutinación en látex ha sido descrita para el serodiagnóstico de la paracoccidioidomicosis, demostrando, en las pruebas a campo, valores de 61-69,5\% de sensibilidad (Brummer \& Castaneda, 1993). La aglutinación en látex demostró una sensibilidad del $73 \%$ y una especificidad del $79 \%$ sin previo tratamiento de la muestra. Sin embargo, en las muestras pretratadas con buffer (2,05\% glucosa, 0,8 \% citrato trisódico, 0,42\% sodio clorhídrico, 0,1\% Tween ${ }^{\circledR} 20$ en agua, $\mathrm{pH}$ 6,4), en una dilución 50:50 e incubadas durante 30 minutos a $37{ }^{\circ} \mathrm{C}$, se produjo un incremento de la especificidad y de la sensibilidad de la prueba hasta un $90 \%$ (Silveira-Gomes, 2012).

El Western blot (WB) es una de las pruebas más sensibles y específicas para detectar respuesta humoral mediada por anticuerpos anti- 
gp43 específicos de paracoccidioidomicosis en caninos (Canteros et al., 2010). En un estudio se demostró que la técnica de WB en humanos es más sensible y rápida que la inmunodifusión doble en gel (Perenha-Viana \& Gonzales, 2012).

En un estudio realizado mediante la prueba de ELISA y la intradermorreacción con el antígeno gp43 de $P$. brasiliensis, se observó que el $80,5 \%$ de los perros de zonas rurales presentaron anticuerpos anti gp43, y que ese resultado fue estadísticamente significativo al compararlo con el $53,6 \%$ de los perros serorreactivos de zonas urbanas (Fontana et al., 2010).

En Brasil se realizó un estudio en perros para detectar anticuerpos específicos contra la glicoproteína gp43 de $P$. brasiliensis mediante el uso de ELISA e inmunodifusión. Se encontró un 54,8 \% de positividad con la prueba de ELISA, indistintamente del sexo, mientras que, cuando las muestras se evaluaron mediante inmunodifusión, se observó un 52,7 \% y 57,6 \% de positividad al antígeno purificado de la gp43 en machos y hembras, respectivamente (Corte et al., 2012).

En una evaluación realizada en gatos en Brasil, mediante el uso de la prueba de ELISA indirecta, la serorreactividad fue del 31,6 \%; sin embargo, no se detectaron animales serorreactivos mediante inmunodifusión (Oliveira et al., 2013).

En la última década se han sumado nuevas técnicas, como la detección rápida del genoma y la microscopía de alta resolución con rayos láser (Conti Díaz, 2010).

\section{Tratamiento}

El itraconazol, administrado durante 6 a 18 meses, es el tratamiento de elección para la forma leve a moderada de la enfermedad. Este antimicótico es un azol de tercera generación que actúa sobre el citocromo P450 y depende de la 1,4a-demetilasa para prevenir la conversión de lanosterol a ergosterol en la membrana del hongo (de Farias et al., 2011).

Se recomienda una dosis de ataque de 5 $\mathrm{mg} / \mathrm{kg} / \mathrm{v}$.o. cada $12 \mathrm{~h}$ durante los primeros 3 a 5 días de tratamiento. En perros, la dosis es de $5 \mathrm{mg} /$ $\mathrm{kg} /$ v.o. cada $24 \mathrm{~h}$, durante los primeros 2 a 3 meses o hasta que desaparezcan los signos de la enfermedad activa. Los gatos pueden requerir 5 $\mathrm{mg} / \mathrm{kg} / \mathrm{v}$.o. cada $12 \mathrm{~h}$ hasta constatar la desaparición de los signos (Ettinger \& Feldman 2004).

Se deben realizar controles mensuales de la concentración sérica de enzimas hepáticas mientras se administra el itraconazol. Es posible que se produzcan incrementos leves a moderados de la alanina transaminasa, la aspartato transaminasa y la fosfatasa alcalina, en un $50 \%$ de los perros y gatos tratados con itraconazol, en especial cuando la dosis alcanza los $10 \mathrm{mg} / \mathrm{kg}$. El tratamiento se debe suspender si el paciente presenta elevación de enzimas hepáticas, anorexia, vómitos o dolor abdominal. El tratamiento puede ser reinstaurado con el $50 \%$ de la dosis cuando las enzimas hepáticas alcanzan sus valores normales.

Con respecto a la anorexia, este es uno de los efectos colaterales usuales del fármaco y es más frecuente en los gatos que en los perros. Deben suministrarse estimulantes del apetito a los gatos o perros que lo necesiten (Morgan et al., 2004). Por otra parte, se comprobó en un estudio prospectivo de 200 pacientes tratados con itraconazol, la elevación de la bilirrubina total y de la $\gamma$-glutamiltransferasa en un 6,2 \% y en un 32,6\%, respectivamente (Levorato et al., 2017).

El itraconazol no atraviesa la barrera hematoencefálica, hematoocular o hematoprostática, aunque alcanza concentraciones adecuadas en la piel; por tal motivo, es uno de los mejores fármacos para tratar la infección cutánea de la enfermedad (Ettinger \& Feldman, 2004; Morgan et al., 2004).

Otro fármaco que suele utilizarse es el ketoconazol, que debe administrarse en dosis de 5$15 \mathrm{mg} / \mathrm{kg} / \mathrm{v}$.o cada $12 \mathrm{~h}$ tanto en perros como en gatos, durante 3 meses. El tiempo de respuesta es mucho menor y las recaídas son frecuentes en comparación con los tratamientos con el itraconazol. Entre los efectos indeseables del ketoconazol se destacan la marcada hepatotoxicidad, la neurotoxicidad y la teratogenicidad (Morgan et al., 2004). No obstante, esto se demostró, mediante pruebas de sensibilidad, en las que la mayoría de los aislamientos $(73,7 \%)$ fueron sensibles a este fármaco (Cermeño et al., 2015).

El fluconazol es otra droga recomendada para el tratamiento, en dosis de 2,5-5 mg/kg/v.o. o de forma intravenosa, cada 24 horas. Este fármaco no requiere la administración de antiácidos y no se ve afectado por la presencia o ausencia de alimentos. Se excreta por vía urinaria, es hidrofílico y atraviesa bien las barreras hematoencefálica, hematoocular y hematoprostática (Ettinger \& Feldman, 2004). El uso de anfotericina B por vía intravenosa es de elección para el tratamiento de las formas sistémicas o graves.

Otra droga de elección es la trimetroprima en asociación con sulfametoxazol. La duración del tratamiento varía según la severidad del caso (1224 meses) (Ettinger \& Feldman, 2004).

En los últimos años, los investigadores hicieron foco en el desarrollo de vacunas de diversos tipos para la prevención de la enfermedad. La inhibición de la inmunidad Th-2 o la estimulación de las citoquinas Th-1 incrementan la eficacia del tratamiento (Travassos \& Taborda, 2012).

Por otra parte, la proteína gp43, el principal antígeno estudiado de $P$. brasiliensis, estimula al IFN- $\gamma$ dependiente de Th-1, responsable de generar protección intratraqueal frente a las levaduras virulentas de $P$. brasiliensis. Los epitopes de T-CD4+ fueron atribuidos a $\mathrm{P} 10$, un péptido interno de gp43 (Travassos \& Taborda, 2012).

$\mathrm{P} 10$ ha sido validado como antígeno protector luego de desarrollar distintos protocolos, con distintos adyuvantes y combinación de 


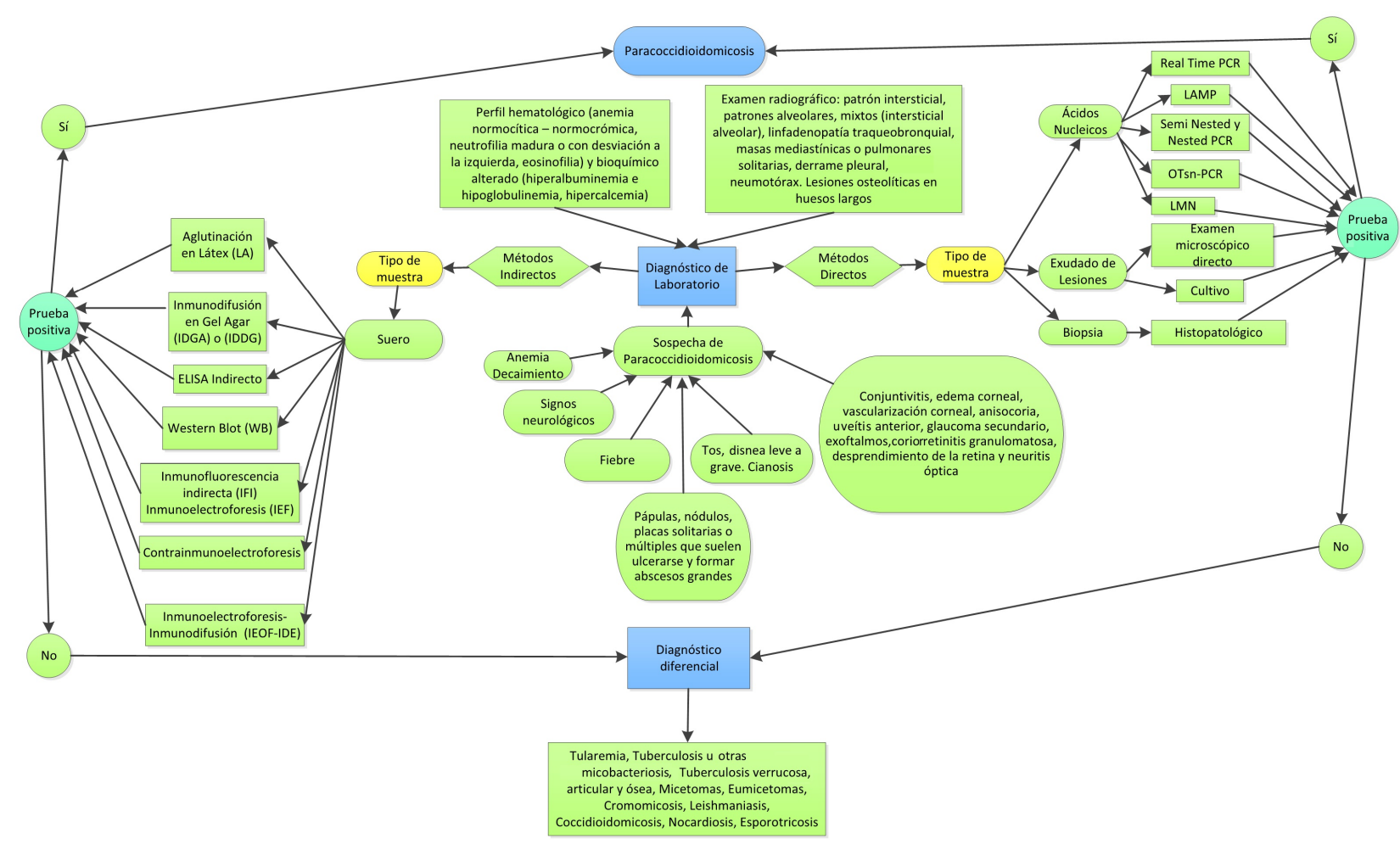

Figura 3. Algoritmo de diagnóstico de la paracoccidioidomicosis.

tratamientos en modelos animales (ratones Balb/c y B10.A). El rol protector de P10 frente a la infección experimental se presenta como una potencial alternativa para alcanzar la inmunización de individuos vulnerables a la infección (Travassos \& Taborda, 2012).

En otro trabajo, se utilizó la inoculación de DNA-hsp65 intramuscular en ratones Balb/c, que indujo un aumento de los niveles de citoquinas Th1. Así, se logró una reducción de la carga fúngica, además de una marcada reducción del grado de fibrosis. En ese estudio, se sugirió que el DNA-hsp65 sería un importante aliado en la prevención y terapia de esta micosis (Ribeiro et al., 2009).

Años más tarde, Ribeiro et al. utilizaron liposomas para la distribución del DNA-hsp65 en el organismo y para tratar la infección fúngica pulmonar. La formulación moderó la respuesta inmune protectora y produjo reducción de la carga fúngica. Una ventaja importante de este ensayo fue que la administración de la formulación se realizó vía intranasal, aceptada más fácilmente por los ratones en estudio (Ribeiro et al., 2013).

\section{Algoritmo de diagnósico}

En la figura 3 se muestra un algoritmo simple para arribar al diagnóstico de la paracoccidioidomicosis. Es recomendable que se obtengan resultados positivos de tres o más pruebas para confirmar el diagnóstico.

\section{Discusión y conclusiones}

Las técnicas de diagnóstico basadas en la glicoproteína de $43 \mathrm{kDa}$ han demostrado su utilidad para la identificación de Paracoccidioides brasiliensis, S1 y PS2. Sin embargo, en el caso de $P$. lutzii se han observado falsos negativos, por lo cual es recomendable emplear más de un antígeno para detectar paracoccidioidomicosis, debido a que esta enfermedad es causada por un complejo de especies (da Silva et al., 2016; Machado et al., 2013).

Aunque en caninos los signos cutáneos solo se presentan en un 30-50 \% de los casos, recientemente en Brasil se describió un caso de paracoccidioidomicosis en una perra Labrador con linfadenitis y lesiones cutáneas. En este caso se emplearon técnicas serológicas, citológicas y moleculares (Headley et al., 2017).

Se deben obtener resultados positivos en, al menos, tres pruebas diferentes para un correcto diagnóstico, ya que existen pruebas que presentan falsos positivos por reacción cruzada con otras 
micosis, entre las que se pueden mencionar la histoplasmosis o la aspergilosis (da Silva et al., 2016).

Se necesitan más investigaciones para comprender el papel de los perros en el ciclo epidemiológico de $P$. brasiliensis, o determinar si simplemente se trata de un hospedador accidental (Headley et al., 2017), ya que los casos diagnosticados en perros y gatos son escasos.

La disponibilidad de varias técnicas diagnósticas favorecerá la realización de investigaciones en animales para conocer mejor la ecología y la biogeografía de la enfermedad. De esta manera se podrá evaluar adecuadamente el riesgo para las personas y, sobre esta base, implementar estrategias de prevención y control (Arantes et al., 2013; De Sousa et al., 2016; Macalupú, 2014).

Las manifestaciones clínicas en caninos y felinos son inespecíficas. Una correcta anamnesis y el empleo de las pruebas diagnósticas disponibles son herramientas que permiten instaurar prontamente el tratamiento, lo que podrá evitar la forma diseminada de esta micosis con sus graves consecuencias.

\section{Conflicto de intereses}

Los autores declaran que no existe conflicto de intereses, incluyendo entre estos últimos las relaciones financieras, personales o de otro tipo con otras personas u organizaciones que pudieran influir de manera inapropiada en el trabajo.

\section{Bibliografía}

Arantes TD, Theodoro RC, Da Graca Macoris SA, Bagagli E. 2013. Detection of Paracoccidioides spp. in environmental aerosol samples. Medical Mycology. 51:83-92.

doi: 10.3109/13693786.2012.698444

Ballesteros A, Beltrán S, Patiño J, Bernal C, Orduz R. 2014. Paracoccidioidomicosis juvenil diseminada diagnosticada en una niña en área urbana. Biomédica. 34:21-8.

doi: 10.7705/biomedica.v34i1.1637

Brummer E, Castaneda E, Restrepo A. 1993. Paracoccidioidomycosis: an update. Clinical Microbiology Reviews. 6:89-117.

Canteros CE, Madariaga MJ, Lee W, Rivas M C, Davel G, Iachini R. 2010. Endemic fungal pathogens in a rural setting of Argentina: seroepidemiological study in dogs. Revista Iberoamericana de Micología. 27:14-9.

doi: 10.1016/j.riam.2009.11.002

Carrasco-Zuber JE, Navarrete-Dechent C, Bonifaz A, Fich F, Vial-Letelier V, Berroeta-Mauriziano D.
2016. Afectación cutánea en las micosis profundas: una revisión de la literatura. Parte 2. Micosis sistémicas. Actas Dermo-Sifiliográficas. 107:80615 .

Cermeño JR, Alvarado P, Mendoza M, Hernández de Cuesta I. 2015. Sensibilidad in vitro de aislados del complejo Paracoccidioides spp. a antifúngicos sistémicos utilizando el método de microdilución. Investigación Clínica. 56:243-64.

Conti-Díaz IA. 2010. A propósito del centenario del descubrimiento de la paracoccidioidomicosis. Principales hitos de la evolución de su conocimiento con especial énfasis en las contribuciones científicas nacionales. Revista Médica Uruguaya. 26:45-50.

Corte AC, Gennari SM, Labruna MB, Camargo LMA, Itano EN, Freire RL, Camargo ZP, Ono MA. 2012. Paracoccidioides brasiliensis infection in dogs from Western Brazilian Amazon. Pesquisa Veterinária Brasileira. 32:649-52.

doi: 10.1590/So100-736X2012000700011

da Silva JF, de Oliveira HC, Marcos CM, Assato PA, Fusco-Almeida AM, Mendes-Giannini MJS. 2016. Advances and challenges in paracoccidioidomycosis serology caused by Paracoccidioides species complex: an update. Diagnostic Microbiology and Infectious Disease. 84:87-94.

doi: 10.1016/j.diagmicrobio.2015.06.004

de Farías MR, Condas LA, Ribeiro MG, Bosco S de M, Muro M D, Werner J, Theodoro RC, Bagagli E, Marques SA, Franco M. 2011. Paracoccidioidomycosis in a dog: case report of generalized lymphadenomegaly. Mycopathologia. 172:147-52. doi: 10.1007/s11046-011-9412-Z

De Sousa L, Borges A, Badell-Lara M, D' Onofrio Pasaporte M, Di Cumpli-Zaghlul M, Díaz-Ortega A, García-Romero F, Machado-Villarreal V. 2016. Morbilidad causada por contacto con animales en Venezuela (2005-2009). Saber. Revista Multidisciplinaria del Consejo de Investigación de la Universidad de Oriente. 28:865-71.

Espinoza Pérez J, Agüero Balbín R, Martínez Meñaca A, Ciorba C, Mora Cuesta V. 2014. Micosis pulmonares. Medicine - Programa de Formación Médica Continuada Acreditado. 11:3949-62.

Ettinger SJ, Feldman EC. 2004. Veterinary internal medicine. 6ta edición. Missouri, EE.UU., Elsevier.

Fontana FF, Dos Santos CT, Esteves FM, Rocha A, Fernandes GF, do Amaral CC, Domingues MA, De Camargo ZP, Silva-Vergara ML. 2010. Seroepidemiological survey of paracoccidioidomycosis infection among urban and rural dogs from Uberaba, Minas Gerais, Brazil. Mycopathologia. 
169:159-65.

doi: 10.1007/s11046-009-9241-5

Gomes GM, Cisalpino PS, Taborda CP, De Camargo ZP. 2000. PCR for diagnosis of paracoccidioidomycosis. Journal of Clinical Microbiology. 38:3478-80.

Headley SA, Pretto-Giordano LG, Di Santis GW, Gomes LA, Macagnan R, da Nobrega DF, Leite KM, De Alcántara BK, Itano EN, Alfieri AA, Ono MA. 2017. Paracoccidioides brasiliensis-associated dermatitis and lymphadenitis in a dog. Mycopathologia. 182:425-34.

doi: 10.1007/s11046-016-0075-7

Hrycyk MF, García Garcés H, Bosco SMG, de Oliveira SL, Márques SA, Bagagli E. 2018. Ecology of Paracoccidioides brasiliensis, $P$. lutzii and related species: infection in armadillos, soil occurrence and mycological aspects. Medical Mycology. doi: 10.1093/mmy/myx142

Imai T, Sano A, Mikami Y, Watanabe K, Aoki FH, Branchini ML, Negroni, R, Nishimura K, Miyaji M. 2000. A new PCR primer for the identification of Paracoccidioides brasiliensis based on rRNA sequences coding the internal transcribed spacers (ITS) and $5 \times 8 \mathrm{~S}$ regions. Medical Mycology. 38:323-6.

Levorato AD, Moris DV, de Souza Cavalcante R, Sylvestre TF, de Azevedo PZ, de Carvalho LR, Mendes RP. 2018. Evaluation of the hepatobiliary system in patients with paracoccidioidomycosis treated with cotrimoxazole or itraconazole. Medical Mycology. 56:531-40.

doi: $10.1093 / \mathrm{mmy} / \mathrm{myx} 80$

Macedo PM, Almeida-Paes R, Almeida MA, Coelho RA, Oliveira Filho MA, Medeiro DM, Gomes-Silva A, Lima JR, Da-Cruz AM, Zancope-Oliveira RM, Valle A. 2018. Fatal septic shock caused by Paracoccidioides brasiliensis phylogenetic species S1 in a young immunocompetent patient: a case report. Revista da Sociedade Brasileira de Medicina Tropical. 51:111-4.

doi: 10.1590/0037-8682-0318-2017

Machado GC, Moris DV, Arantes TD, Silva LRF, Theodoro RC, Mendes RP, Vicentini AP, Bagagli E. 2013. Cryptic species of Paracoccidioides brasiliensis: impact on paracoccidioidomycosis immunodiagnosis. Memórias do Instituto Oswaldo Cruz. 108:637-43.

Marques SA. 2012. Paracoccidioidomycosis. Clinics in Dermatology. 30:610-5.

doi: 10.1016/j.clindermatol.2012.01.006

Mendes-Giannini MJS, Camargo ME, Lacaz, CS, Ferreira AW. 1984. Immunoenzymatic absorption test for serodiagnosis of paracoccidioidomycosis. Journal of Clinical Microbiology. 20:103-8.

Morgan R, Bright R, Swartout M. 2004. Clínica de pequeños animales. Madrid-España, Elsevier.

Oliveira GG, Belitardo DR, Balarin MR, Freire RL, Camargo ZP, Ono MA. 2013. Serological survey of paracoccidioidomycosis in cats. Mycopathologia. 176:299-302. doi: 10.1007/s11046-013-9681-9

Perenha-Viana MC, Gonzales IA, Brockelt SR, Machado LN, Svidzinski TI. 2012. Serological diagnosis of paracoccidioidomycosis through a Western blot technique. Clinical and Vaccine Immunology. 19:616-9. doi: 10.1128/CVI.05693-11

Pérez D, Oviedo J, Gill S. 2014. Paracoccidioidomicosis: características clínicas de 94 casos. Revista Americana de Medicina Respiratoria. 14:20-7.

Pitz A de F, Koishi AC, Tavares ER, De Andrade FG, Loth EA, Gandra RF, Venancio EJ. 2013. An optimized one-tube, semi-nested PCR assay for Paracoccidioides brasiliensis detection. Revista da Sociedade Brasileira de Medicina Tropical. 46:7835 .

Restrepo A, Moncada LH. 1972. Indirect fluorescent-antibody and quantitative agar-gel immunodiffusion tests for the serological diagnosis of paracoccidioidomycosis. Applied Microbiology. 24:132-7.

Restrepo A, Moncada LH. 1974. Characterization of the precipitin bands detected in the immunodiffusion test for paracoccidioidomycosis. Applied Microbiology. 28:138-44.

Ribeiro AM, Bocca AL, Amaral AC, Faccioli LH, Galetti FC, Zarate-Blades CR, Figueiredo F, Silva CL, Felipe MS. 2009. DNAhsp65 vaccination induces protection in mice against Paracoccidioides brasiliensis infection. Vaccine. 27:606-13.

Ribeiro AM, Souza AC, Amaral AC, Vasconcelos NM, Jerónimo MS, Carneiro FP, Faccioli LH, Felipe MS, Silva CL, Bocca AL. 2013. Nanobiotechnological approaches to delivery of DNA vaccine against fungal infection. Journal of Biomedical Nanotechnology. 9 (2):221-30.

Rojas-Jaimes J, Castillo-Córdova R, TárragaGonzáles D. 2015. Paracoccidiomicosis en el sistema nervioso central: reporte de un caso. Revista Peruana de Medicina Experimental y Salud Pública. 32:183-6.

Schaer M. 2006. Medicina clínica del perro y del gato. Barcelona, España, Masson. 
Silveira-Gomes F, Marques-da Silva SH. 2012. Effects of pretreating serum samples on the performance of a latex agglutination test for serodiagnosis of paracoccidioidomycosis. Clinical and Vaccine Immunology. 19:386-90.

doi: 10.1128/CVI.05274-11

Silveira LH, Domingos IH, Kouchi K, Itano EN, Silva EA, Landgraf VO, Werneck SM, Camargo ZP, Ono MA. 2006. Serological detection of antibodies against Paracoccidioides brasiliensis in dogs with leishmaniasis. Mycopathologia. 162:325-9.

doi: 10.1007/s11046-006-0046-5

Teixeira MM, Theodoro RC, Nino-Vega G, Bagagli E, Felipe MSS. 2014. Paracoccidioides species complex: ecology, phylogeny, sexual reproduction, and virulence. PLoS Pathogens, 10: e1004397.

doi: 10.1371/journal.ppat.1004397

Thompson MS. 2008. Diagnóstico diferencial clínico en pequeños animales. Madrid-España, Elsevier-Saunders.
Travassos L, Taborda, CP. 2012. Paracoccidioidomycosis vaccine. Human Vaccines \& Immunotherapeutics. 8:1450-3. doi:10.4161/hv.21283

Winn WC, Allen SD, Janda WA, Koneman EW, Procop GW, Schrenckenberger PC, Woods GL. 2008. Koneman. Diagnóstico microbiológico texto y atlas en color. Buenos Aires, Médica Panamericana.

Yarzábal LA, Biguet J, Vaucelle T, Andrieu S, Torres JM, Da Luz S. (1973). Analisis Inmunoquimico de extractos solubles de Paracoccidioides brasiliensis. Sabouraudia: Journal of Medical and Veterinary Mycology, 11(1), 80-8.

doi: 10.1080/00362177385190171

Zurita Macalupú S. 2014. Esporotricosis y paracoccidioides en Perú: experiencias en prevención y control. Revista Peruana de Medicina Experimental y Salud Pública. 31:352-7. 